\title{
Autosomal recessive severe congenital neutropenia due to G6PC3 deficiency
}

INSERM

\section{Source}

INSERM. (1999). Orphanet: an online rare disease and orphan drug data base. Autosomal recessive severe congenital neutropenia due to G6PC3 deficiency. ORPHA:331176

Autosomal recessive severe congenital neutropenia due to G6PC3 deficiency is a rare, genetic, primary immunodeficiency disorder characterized by increased susceptibility to recurrent, life-threatening bacterial infections, in association with typically severe neutropenia in peripheral blood and bone marrow and a prominent ectatic superficial vein pattern, resulting from recessively inherited mutations in the G6PC3 gene. Cardiac malformations (e.g. atrial septal defects, patent ductus arteriosus,valvular defects), urogenital anomalies (incl. cryptorchidism), growth and developmental delay, facial dysmorphism (e.g. frontal bossing, upturned nose, malar hypoplasia), and intermittent thrombocytopenia are frequently associated. 